\title{
Shigellosis
}

\section{Another sexually transmitted disease?}

\author{
LEWIS M. DRUSIN, GAIL GENVERT, BARBARA TOPF-OLSTEIN, AND ELLEN \\ LEVY-ZOMBEK \\ Departments of Public Health, Medicine, and Epidemiology, The New York Hospital, USA
}

\section{Summary}

Following the clinical observation that there appeared to be an association between shigellosis and male homosexuality, the medical records of II3 patients at The New York Hospital were reviewed retrospectively. Of the 38 males studied who were between the ages 19 and $6 \mathrm{I}$, seventeen were homosexual ( 44.7 per cent.). Only one of the matched controls was homosexual. Of the men with shigellosis who had a history of foreign travel, ro per cent. were homosexual; however, among the patients without a travel history, 57. I per cent. were homosexual $(P<0.05)$. For male patients with shigellosis who do not have an appropriate travel history, the physician should expand his epidemiological investigation to include sexual contacts. Men and women who perform rectal intercourse should be cautioned to abstain from this activity until their stool cultures are negative for shigella. If a male patient with shigellosis is homosexual, he should be screened for other sexually transmitted diseases such as syphilis, gonorrhoea, hepatitis B, and amoebiasis.

\section{Introduction}

Sexually transmitted diseases are clinically important microbial infections. Reported cases of both syphilis and gonorrhoea have increased annually in the United States (American Social Health Association, 1975). Herpes progenitalis, although not the cause of a reported disease, appears to be increasing in incidence. Recently, a sexual mode of transmission has been described for other diseases such as hepatitis B (Szmuness, Much, Prince, Hoofnagle, Cherubin, Harley, and Block, 1975), streptococcal pyoderma

Received for publication April 13, 1976

Address for reprints: Prof. L. M. Drusin, M.D., M.P.H., Department of Public Health, New York Hospital, Cornell Medical Center, 525 East 68th Street, New York, N.Y. 10021, U.S.A.
(Drusin, Wilkes, and Gingrich, 1975), and amoebiasis (Kean, 1976). This paper discusses an association between shigellosis and male homosexuality.

\section{Material and methods}

The medical records of all patients from whom shigella was recovered from a bacterial culture of their stool and who were either admitted to The New York Hospital or seen in the outpatient clinic during the 5 -year period September, 1970, to August, 1975, were reviewed retrospectively. From this group, the study population was defined as males who were between the ages of 15 and 65 at the time of their infection. Hospital charts on all these men were examined for birth date, discharge date for inpatients, travel history, and sexual preference. Uninfected controls were individually matched for sex, marital status (separated and divorced were considered single), and a date of birth that fell within 2 years of the date of birth of the patient. For inpatients, the control was the next person discharged who fitted the matching criteria. For outpatients, the control was the man with the next consecutively assigned history number. Hospital charts for the controls were reviewed for sexual preference. Both cases and controls were classified as homosexual only if this was specifically written in their hospital record, and they were compared for demographic characteristics such as race, religion, and occupation. The $\chi^{2}$ test for comparing two percentages was used in the data analysis (Huntsberger and Leaverton, 1970).

\section{Results}

During the 5-year study period, 113 patients had shigella identified in their stool after bacterial culture. 38 males in the appropriate age group were studied.* There were eighteen inpatients and twenty outpatients whose ages ranged from 19 to 61 years. A review of their medical records identified seventeen homosexual men ( 44.7 per cent.). Only one of the 38 matched controls was described as homosexual. A comparison of cases and controls for race, religion and occupation failed to reveal significant differences between the two groups. All of the cases and controls

*One additional male was not included in this study because his medical record was lost. 
lived in the New York Metropolitan Area. The Figure shows the distribution of the study population by sexual orientation and foreign travel. Five patients travelled to Mexico and the others visited Guatemala, Haiti, South America, Egypt, and France. One heterosexual male, who gave a history of oro-genital contact with his girl friend and who had recently returned from Mexico with dysentery, is included in the travel group. Of the men with shigellosis who had a history of foreign travel, only 10 per cent. were homosexual; among the patients without a travel history, 57.1 per cent. were homosexual. These results are significantly different $\left(\chi^{2}{ }_{1}=4.85\right.$; $P<0.05)$. When the organisms causing infection in the group that did not travel were examined, there was no appreciable difference in the frequency distribution of Shigella sonnei and Shigella flexneri between the homosexual and heterosexual patients.

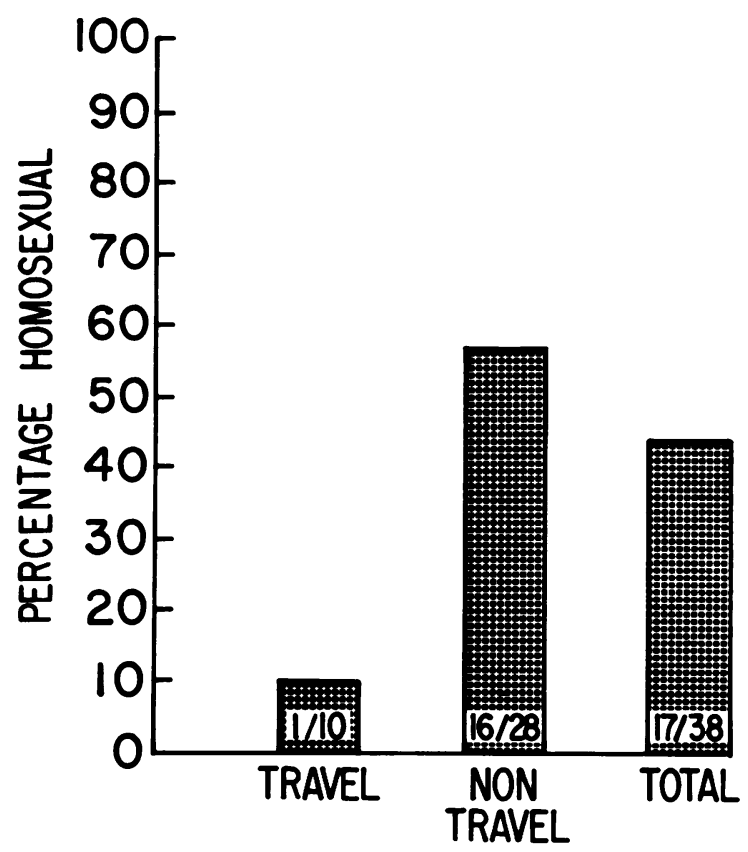

FIGURE Distribution of male patients with shigellosis by sexuality and travel

\section{Discussion}

It is difficult to use a retrospective case-control study to establish an association between shigellosis and male homosexuality. Physicians do not frequently comment on the sexual orientation of their patients in the medical record. As a generalization, the medical record for inpatients was more detailed than the corresponding information for outpatients. If there was a bias introduced by the medical record, it was probably towards an underestimate of the degree of homosexuality in the study population. Since shigellosis was not generally considered a sexually transmitted disease during our study period, it seemed reasonable to assume that the likelihood of a physician taking a sexual history from either a case or the age-matched control was probably about equal. If the control group can be considered representative of the New York Hospital patient population, then the extraordinary preponderance of male homosexuals among the patients with shigellosis cannot be explained by the frequency distribution of homosexuals in the hospital's patient population.

This study was limited to males between the ages of 15 and 65 years because the sexual behaviour pattern of males outside this age range might be subject to other variables which would not make them comparable to the majority of sexually active males. Females were not included in this study because it is extremely difficult to determine their sexual orientation from a retrospective review of medical records. Unfortunately, this type of study cannot be used to describe the incidence of homosexuality in male patients with shigellosis in the general population, define a causal relationship, or estimate the risk of infection with shigella correlated with the duration of homosexuality.

Although it is also impossible to use this kind of retrospective study to identify the specific type of sexual behaviour that is associated with the greatest risk of infection with shigella, other investigators have commented on possible aetiologies. Dritz and Back (1974) reported a sexually transmitted outbreak of enteritis due to Shigella flexneri $2 a$ in a group of adult men associated with San Francisco's homosexual community. They speculated that oro-genital contact was the probable method of transmission. Szmuness and others (1975), on the other hand, in a discussion of the role of sexual behaviour in the spread of hepatitis B infection, reported significant epidemiological data showing a high prevalence of hepatitis B in male homosexuals whose sexual activity included rectal intercourse. Homosexual males whose predominant sexual activity was oro-genital contact had a prevalence of hepatitis B similar to heterosexuals. In an epidemiological study of sexually transmitted diseases on a university campus (Drusin, Magagna, Yano, and Ley, 1974), rectal intercourse as a routine part of the sexual behaviour pattern in heterosexuals was found to be an important risk factor for acquiring gonorrhoea and syphilis.

The observation that male patients without an adequate travel history to explain their shigella infection were predominantly homosexual is important to the practising physician. Now, instead of restricting his epidemiological investigation to household members, the physician must also inquire about sexual contacts. Since many male homosexuals have a large number of sexual partners, one homosexual patient 
with shigellosis could be responsible for widespread dissemination of his disease. Men and women who perform rectal intercourse should be told to abstain from this activity until their stool cultures are negative for shigella. Because a high incidence of syphilis and gonorrhoea has been reported among homosexuals (British Cooperative Clinical Group, 1973), it would be important to perform screening tests for these diseases and other sexually transmitted illnesses such as hepatitis $B$ and amoebiasis in patients with shigellosis who might be homosexual.

\section{References}

American Social Health Association (1975) 'Today's VD Control Problem', p. 11. New York
British Cooperative Clinical Group (1973) Brit. $\mathcal{F}$. vener. Dis., 49, 329

DrItz, S. K., and BACK, A. F. (1974) New Engl. $\mathcal{F}$. Med., 291, 1194 (letter)

Drusin, L. M., Magagna, J., Yano, K., and Ley, A. B. (1974) Amer. F. Epidemiol., 100, 8

, WILKES, B. M., and GINGRICH, R. D. (1975) Brit. f. vener. Dis., 51, 61

Huntsberger, D. V., and Leaverton, P. E. (1970) 'Statistical Inference in the Biomedical Sciences,' p. 93. Allyn and Bacon, Boston

KEAN, B. H. (1976) N.Y. St. F. Med., 76, 930

Szmuness, W., MuCh, M. I., Prince, A. M., Hoofnagle, J. H., Cherubin, C. E., Harley, E. J., and Block, G. H. (1975) Ann. intern. Med., 83, 489 